\title{
INTRODUCTION
}

\section{Can policies enhance fertility in Europe?}

\author{
Anne H. Gauthier and Dimiter Philipov*
}

\section{Introduction}

The reach and the persistence of low levels of fertility throughout Europe and other parts of the world in recent decades have raised much concern among governments: concerns about the impact of such low levels of fertility on economic growth, labour force supply and health care, but also concerns-or rather questions - about whether or not governments should intervene to attempt to increase fertility (Caldwell et al. 2002). The possibility of governmental intervention to raise fertility is a highly controversial issue in most countries as the decision to have children is usually seen as a strictly private one (Barach et al. 2005). However, the situation is rendered more complicated when confronted to data showing that parents would like to have more children but that they are prevented from doing so because of financial and work-related obstacles (Goldstein et al. 2003). Our objective at the International Conference that took place in December 2007 in Vienna, however, was not to question whether or not governments should intervene, but rather to ask the question of whether or not policies can enhance fertility. ${ }^{1}$ This seemingly easy question is in fact very difficult to answer for several reasons. First, while countries provide families with a wide range of support, very few of these policy measures have an explicit pronatalist objective. In most cases, they instead aim at partly compensating parents for the cost of children, at reducing income inequality, at encouraging women to join the labour force and/or at increasing gender equality. Second, while individuals may consider policies when deciding to have a first or

* Anne H. Gauthier, (author of correspondence), Department of Sociology, University of Calgary, 2500 University Drive NW, Calgary, Alberta T2N 1N4, Canada. Email: gauthier@ucalgary.ca

Dimiter Philipov, Vienna Institute of Demography, Austrian Academy of Sciences, Vienna, Austria.

1 The conference was organised by the Vienna Institute of Demography with the support of the Austrian Red Cross, the City of Vienna, and the Federation of Austrian Industry. With the exception of the contributions by Pailhé et al. and Thévenon (which were commissioned after the conference), all papers presented in this volume were peer-reviewed.

DOI: 10.1553/populationyearbook2008s1 
subsequent child, many other factors are also weighed in including non-financial ones. And finally, while individuals may have preferences regarding the ideal family size and the ideal timing for having children, these preferences tend to vary over the individuals' life-course, thus further complicating the task of scholars trying to assess the potential impact of policies.

The set of papers included in this volume aimed at shedding further light on this question by reflecting on the experience of some countries, by examining the role of policies in relation to other fertility determinants, and by analysing various indicators of fertility. The structure of this introductory article is as follows. In Section 2, we provide the background to this special issue by first presenting data on fertility and then by attempting to link cross-national differences in fertility to other economic, social and institutional differences. This first broad brush stroke approach is strictly descriptive but helps situate low fertility in a broader social and economic context. In Section 3, we then turn to the question of a possible gap between fertility preferences and actual fertility and also examine the reasons for low fertility. In Sections 4, 5 and 6 we examine the possible links between policies and fertility, first by looking at financial support for families, and then at work- and gender-related policies. We conclude in Section 7 by indicating future avenues of research.

\section{A broad brush stroke approach}

Despite the fact that European countries share a common decline in fertility to levels below replacement, cross-national variations in the actual level of fertility remain large. In 2006, the difference was close to 0.8 children per woman, from a minimum of 1.19 in Bosnia-Herzegovina to 2.08 in Iceland. ${ }^{2}$ Then again, these figures are based on the total period fertility rate (TFR) and are likely to overestimate the actual (cohort) fertility differences between countries (something we discuss later in this paper). Figure 1 further illustrates the wide cross-national differences in fertility levels. It also reveals an interesting geographical clustering of countries with higher-than-average levels in the Nordic countries (but also in France, the United Kingdom and Ireland) and lower-than-average levels in southern and eastern Europe.

While these geographical differences are well known and have been documented elsewhere (see for example Billari and Kohler 2004), they are a useful starting point for our discussion of policies and the role of institutions. In particular, it is probably not a coincidence that the relatively higher levels of fertility observed in the Nordic countries coexist with a relatively high standard of living, low levels of poverty and unemployment, a high degree of gender equality and a high level of governmental support for families. In contrast, the low levels

2 A lower figure was reported for San Marino $($ TFR $=1.11$. 
of fertility observed in eastern Europe coexist with lower levels of development, higher unemployment rates and economic uncertainty, lower degrees of gender equality and lower levels of support for families. It is difficult to quantify all of these dimensions with cross-nationally comparable indicators. Table 1 is an attempt at doing so via three widely used indicators: the UNDP Human Development Index, the UNDP Gender Empowerment Index and an overall measure of governmental support for families (based on Gauthier 2005). The data in Table 1 have furthermore been grouped into six geographical regions that reflect the clusters observed in the previous map. France appears on its own in this table in view of its higher level of fertility (as compared to its neighbours) and its higher level of support for families.

\section{Figure 1:}

\section{Total fertility rate in European countries, 2006}

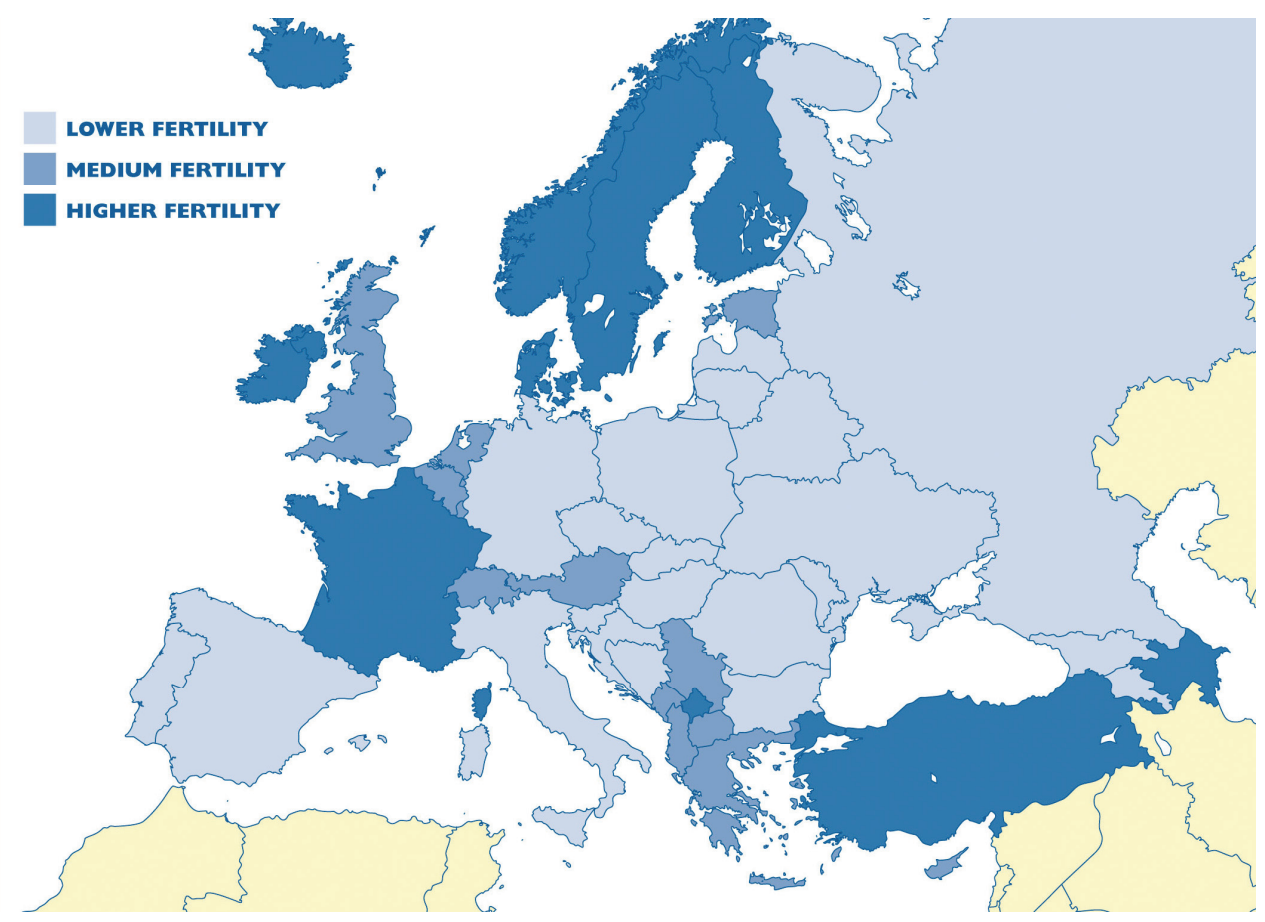

Note: The levels of total fertility rate (TFR) shown on the map are constructed as follows: Lower fertility: TFR below 1.40; Medium fertility: TFR between 1.40 and 1.79; Higher fertility: TFR at 1.80 and above.

This exercise is obviously illustrative and rather qualitative, but nonetheless nicely contrasts the Nordic countries with the lowest-low fertility countries of southern and eastern Europe. It also suggests how the countries' economic, social and institutional context may produce distinct fertility levels. However, the fit is not perfect. For example, it does not fully explain the persistence of higher levels of fertility in the English-speaking countries despite an average score on the 
Gender Empowerment index and a low level of state support for families. The explanation for these countries lies probably somewhere else, possibly in the higher level of conservative family attitudes found in English-speaking countries (Inglehart and Baker 2000) ( $^{3}$ and in the lower level of expectation towards governmental support for families. ${ }^{4}$ This table furthermore reveals some similarities between the southern and eastern regions with regard to the four indicators presented in Table 1. These two regions differ widely in terms of other indicators of family formation though, especially their divorce rate, mean age of entry into motherhood and percentage of children born out of wedlock. ${ }^{5}$ But what the table does suggest is that policies directed at each of these three dimensions may be potential levers of fertility.

Table 1:

Fertility and economic/institutional context, 2006

\begin{tabular}{lcccc}
\hline \multicolumn{1}{c}{ Regions $^{1}$} & Fertility & $\begin{array}{c}\text { Human } \\
\text { Development } \\
\text { Index }\end{array}$ & $\begin{array}{c}\text { Gender } \\
\text { Empowerment } \\
\text { index }\end{array}$ & $\begin{array}{c}\text { State support } \\
\text { for families }\end{array}$ \\
\hline Nordic & + & + & + & + \\
France & + & + & $\bullet$ & + \\
English-speaking & + & + & $\bullet$ & - \\
Western & - & - & $\bullet$ & - \\
Southern & - & - & - & - \\
Eastern & - & - & - & - \\
\hline
\end{tabular}

Where: + : higher than average; $\bullet$ : average; -: lower than average

Note: 1 - Nordic $=$ Denmark, Finland, Iceland, Norway, Sweden; English-speaking = Ireland, UK, USA; Western

= Austria, Belgium, Germany, Netherlands, Switzerland; Southern = Greece, Italy, Portugal, Spain; Eastern = Belarus, Bulgaria, Czech Republic, Estonia, Georgia, Hungary, Latvia, Lithuania, Poland, Romania, Russia, Slovakia, Slovenia, Ukraine.

Source: Own calculation from data published in the European Demographic Data Sheet 2008 and data from the UNDP Human Development Report (online) and from Gauthier (2005).

We will discuss later in this paper the evidence regarding the links between various policies and fertility. Below, we first turn to the issue of fertility indicators and reasons for low fertility.

3 This argument applies more specifically to the United States of America than to other Englishspeaking countries.

4 The argument here being that if public opinion endorses the ideologies of the free market and the private nature of families, then there will be less expectations regarding the levels of governmental support for families. In other words, while low levels of governmental support for families may be an obstacle to fertility in social democratic and conservative welfare states, it may matter less in liberal welfare states.

5 We should note that there are also wide within-group differences with regard to these indicators of family formation but the discussion of these differences is beyond the scope of this paper. 


\section{Fertility indicators and reasons for low fertility}

\section{TFR vs. tempo-adjusted fertility}

Postponement of births, manifested by an increase in the parity-specific mean age at fertility, is known to depress the observed period TFR (Bongaarts and Feeney 1998). Various measures have been suggested in the literature to correct this socalled tempo effect. The figures reported in the first two columns of Table 2 are based on the formula proposed by Bongaarts and Feeney (1998). They reveal that the adjusted TFR approaches replacement level in the Nordic countries, France and the English-speaking countries, but that it is considerably lower in eastern and particularly in southern Europe. Moreover, the tempo distortion (adjusted minus observed TFR) is very low in the countries known for their supportive family policies (the Nordic countries and France). What these regional differences suggest is that the lower levels of fertility observed in southern and eastern Europe may reflect either a lower preference, or desire, for fertility, or higher barriers to fertility. These factors may indeed be key to understanding regional differences within Europe. However, as seen below, the measurement of preferences and barriers is not an easy task.

\section{Fertility ideals vs. actual fertility}

Preferences for children, or norms regarding ideal family size, have been the subject of much investigation but they remain very difficult to measure for a variety of reasons. In particular, there is a crucial distinction between what is perceived as being ideal in one's own society and what is perceived as being ideal for oneself (Testa 2007). Furthermore, fertility ideals tend also to vary substantially over the life-course (Quesnel-Vallée and Morgan 2003). Keeping these caveats in mind, Table 2 reports data on general and personal fertility ideals. 6 What is noticeable in this table is that the data on ideal family size match those on actual fertility quite nicely: in other words, what we observe is that higher values of ideal family size are found in the three regions that have higher than average fertility while lower values are instead found in the two regions with lower than average fertility. It is also noticeable that fertility ideals are all above replacement level in the six broad regions represented here (although they are considerably lower in specific countries (Goldstein et al. 2003; Testa 2006)).

The comparison of fertility ideals and actual fertility is routinely done in the literature, with the results usually being interpreted in terms of barriers to fertility (Balter 2006). The gap between personal ideal family size and the tempo-adjusted fertility appears in the last column of Table 2. The figures are somewhat surprising in showing that the gap is as high in the three high fertility regions as in

The data on general fertility ideals are based on the question: "Generally speaking, what do you think is the ideal number of children for a family?", while the data on personal fertility ideals are based on the question: "And for you personally, what would be the ideal number of children you would like to have or would have liked to have had?" 
the eastern region. In contrast, it is much larger in southern Europe suggesting the possible presence of larger barriers to fertility.

Table 2:

Fertility ideals and actual fertility, 2006

\begin{tabular}{lccccc}
\hline \multicolumn{1}{c}{ Regions $^{1}$} & $\begin{array}{c}\text { Total } \\
\text { period } \\
\text { fertility rate }\end{array}$ & $\begin{array}{c}\text { Tempo- } \\
\text { adjusted } \\
\text { fertility rate }\end{array}$ & $\begin{array}{c}\text { General } \\
\text { fertility } \\
\text { ideals }^{2}\end{array}$ & $\begin{array}{c}\text { Personal } \\
\text { fertility } \\
\text { ideals }^{2}\end{array}$ & $\begin{array}{c}\text { Gap (personal } \\
\text { ideals }- \\
\text { adjusted TFR) }\end{array}$ \\
\hline Nordic & 1.85 & 1.96 & 2.60 & 2.65 & .69 \\
France & 1.98 & 2.07 & 2.49 & 2.59 & .52 \\
English-speaking & 1.87 & 2.08 & 2.69 & 2.76 & .68 \\
Western & 1.57 & 1.75 & 2.18 & 2.23 & .48 \\
Southern & 1.37 & 1.51 & 2.27 & 2.31 & .80 \\
Eastern & 1.34 & 1.68 & 2.31 & 2.26 & .58 \\
\hline
\end{tabular}

Notes: 1- Nordic: Denmark, Finland, Sweden; English-speaking: Ireland, UK; Western: Austria, Belgium, Germany, Luxembourg, Netherlands; Southern: Greece, Italy, Portugal, Spain; Eastern: Bulgaria, Croatia, Czech Republic, Estonia, Hungary, Latvia, Lithuania, Poland, Romania, Slovakia, Slovenia. 2- Female respondents age 15 and above.

Source: Authors' own calculation from data published in Testa (2006).

\section{Reasons for low fertility}

Bongaarts (pp. 39-55) considers the gap between ideal and actual fertility as an indicator for the existence of barriers to fertility. Along with the tempo effect, he identifies economic, social and biological obstacles that prevent people from realising their reproductive preferences. Policies may aim at mitigating the effect of some of these obstacles. Identification of these obstacles is a difficult task that demographers face (it remained out of the scope for Bongaarts' paper). The problem here is that not only many reasons may have led individuals to postpone childbearing or to restrict family size, but there is also the obvious risk of posthoc rationalising (i.e. to rationalise a decision that took place at an earlier period of life). Keeping in mind these limitations, Table 3 presents data on the perceived relevance of various circumstances in the decision to have children. The data come from the 2006 Eurobarometer survey and are the answers to the question: "According to you, how important is each of the following in the decision on whether to have or not to have alanother child?" Only results for female respondents are reported here.

Two results are particularly striking in this table. First, there is the very low relevance given to economic and work circumstances by respondents in the Nordic region, probably a reflection of their relative high standard of living but also of the security provided by the welfare system in case of various contingencies. Second, and in contrast to the Nordic region, there is the very high relevance given to the same two sets of circumstances by respondents in southern and eastern European countries. In fact, respondents in the southern and eastern regions gave high ranking to all items. This result not only distinguishes respondents from these two regions from the others, but also suggests the possible 
presence of bigger barriers to fertility in these two regions. The western region stands again in the middle on all items with the exception of the last one.

Table 3:

Relevance given to different circumstances in the decision to have children, 2006 (female respondents aged 15 to 39$)^{1 \text { a }}$

\begin{tabular}{lcccc}
\hline \multicolumn{1}{c}{ Regions $^{2}$} & $\begin{array}{c}\text { Economic } \\
\text { circumstances }\end{array}$ & $\begin{array}{c}\text { Mother's and } \\
\text { father's work }\end{array}$ & $\begin{array}{c}\text { Health and } \\
\text { supportive } \\
\text { partner }\end{array}$ & $\begin{array}{c}\text { Child care } \\
\text { provision and } \\
\text { parental leave }\end{array}$ \\
\hline Nordic & 29.9 & 28.2 & 68.8 & 50.3 \\
France & 52.0 & 37.5 & 65.7 & 42.5 \\
English-speaking & 60.3 & 50.5 & 70.8 & 54.3 \\
Western & 47.7 & 45.1 & 70.3 & 47.2 \\
Southern & 67.4 & 66.4 & 78.5 & 61.1 \\
Eastern & 73.4 & 64.8 & 81.6 & 65.9 \\
\hline
\end{tabular}

Notes: 1- Percentage answering 'very important' to a given item; 2- Same countries as in Table 2; 3- Includes financial situation, costs of children and housing conditions.

Source: Authors' own calculation from data published in Testa (2006).

\section{Financial support for families}

The previous result suggests that economic circumstances may be a barrier to fertility - at least in some countries. Perhaps not surprisingly, governments in different countries have implemented various financial measures in an attempt at encouraging parents to have more children, ranging from birth bonuses and tax breaks for children to more generous allowances to higher-parity births. In recent years, such measures have, for example, been introduced in Italy (see the paper by Boccuzzo et al. in pp. 125-147), Australia (Lunn and Wilson 2008), Russia (CBS news 2007) and Korea (Korea Herald 2003). However, the empirical literature suggests that such measures tend to have very little impact on fertility and that most of the impact tends to be short-term (Gauthier 2007). What seems to be happening is that baby bonuses and other such incentives tend to encourage parents who were already intending to have a child to have this child earlier rather than later, and that they have in contrast little impact on individuals who were not at all planning to have another child (see for example Gans and Leigh 2007). On the other hand, the literature is not unanimous on this topic. Studies of the birth bonus in the province of Quebec in Canada, for example, suggest a positive impact on fertility — but at a rather high cost per child (Kim 2007; Milligan 2002). An analysis of the effect of a baby bonus in the Italian province of Friuli-Venezia Julia, carried out by Boccuzzo et al. (pp. 125-147), shows that the baby bonus contributed to an increase in fertility of women with higher parity and lower education. 
And even if single policy measures, such as birth bonuses, are not sufficient to make a substantial difference in a country's fertility level, whole packages of financial support for families may be more successful. The analysis by Bradshaw and Finch (2006) suggests that this could indeed be the case, at least on the basis of bivariate analyses. Differences across countries are in fact large when it comes to financial support for families and they vary depending on the actual indicator used. Figure 2 presents data on cash support for families for twenty-six OECD countries for two such indicators: cash support based on the disposable income of families with children and childless couples (graph on the left-hand side) and expenditures on families as a percentage of national income (graph on the righthand side). The data have furthermore been arranged by region, in line with the groupings used earlier in this introduction. Despite non-negligible within-region variations, the data nonetheless reveal a certain gradient with higher-than-average support in the Nordic countries (and also in western European ones) and lower support in countries of eastern and southern Europe.

Figure 2:

Cash benefits for families with children 2003

Cash support for families

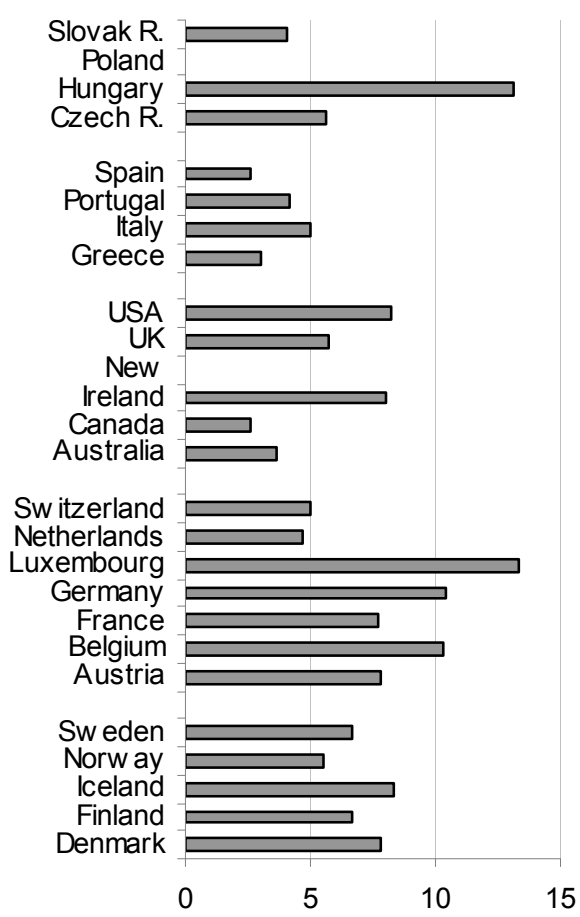

Social expenditures on families as a percent of gross national income

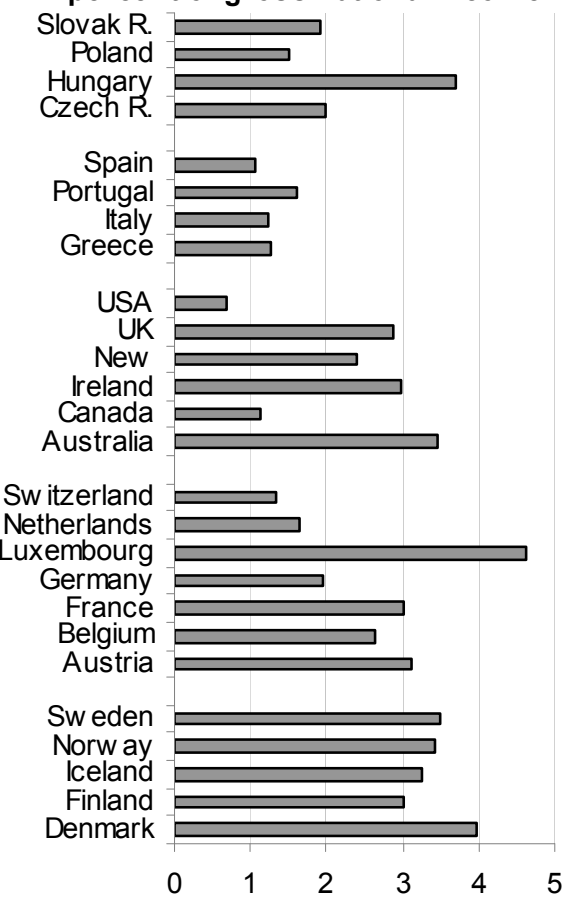

Source: OECD online tax-benefit calculator. Accessed at www.oecd.org.

Note: The data refers to the additional disposable income of a dual-earner two-child family as compared to the disposable income of dual-earner childless family (in both cases one of the spouse earns $100 \%$ of the average earnings and the other $67 \%$ ). 
This ranking of countries is yet one more indication that support for families may indeed matter (in that it correlates with the country ranking on fertility). What may also strongly matter for families, however, are the stability of this financial support and the status of the overall economy (including job security). This argument is very relevant in the case of eastern and central European countries where the transitional economies as well as numerous changes to the countries' family policies may have negatively affected couples' plans to have children (Rostgaard 2004; Stewart and Huerta 2006; Saxonberg and Szelewa 2007). ${ }^{7}$

\section{Work- and gender-related policies}

The other area of family policy that has attracted much attention on the political scene since the 1990s is that of work-family reconciliation. This has been particularly the case in the European Union with the adoption of a Council Recommendation on child care (March 1992) and a Council Resolution on the balanced participation of women and men in family and working life (June 2000). Specific targets for child care provision were furthermore stated by the European Council of Barcelona (in March 2002) and by the European Council in its European Pact for Gender Equality (in March 2006): the aim being to remove disincentives to female labour participation (Špidla 2007). Partly as a result of these initiatives, but also driven by an overall wish to better support working parents in their combination of work and family responsibilities, most countries have introduced, or extended, various policies in recent years. Figures 3 and 4 summarise the national provisions regarding parental leave and child care.

Cross-national differences are relatively large including within the different regions analysed earlier. Overall regional characteristics are therefore less clear. Nonetheless, and in general, the Nordic countries stand out in their large support for working parents through a combination of long parental leave and relatively high child care coverage. At the other extreme of the distribution, one finds the English-speaking countries and southern European countries, both characterised by a low level of support for working parents. The consequences of theses regional and national differences for families are large especially for women. Sigle-Rushton and Waldfogel $(2007 \mathrm{a}, \mathrm{b})$ have for example estimated that the

This is a very complex issue which cannot be fully addressed in this paper. What we do know, however, is four-fold: first, that most eastern and central European countries have had substantially reduced welfare spending in the immediate post-Communist era, second, that access to child care has been seriously reduced, third, that there have been reduced opportunities for women's employment, and fourth, that family income continues to be low in most of these countries. Taken together, these factors may have contributed to the decline and persistence of very low fertility. 
penalties associated with motherhood tend to be smallest in the Nordic countries and largest in continental Europe (including southern Europe). ${ }^{8}$

Figure 3:

Maternity, paternity and parental leave, as of 2005-6

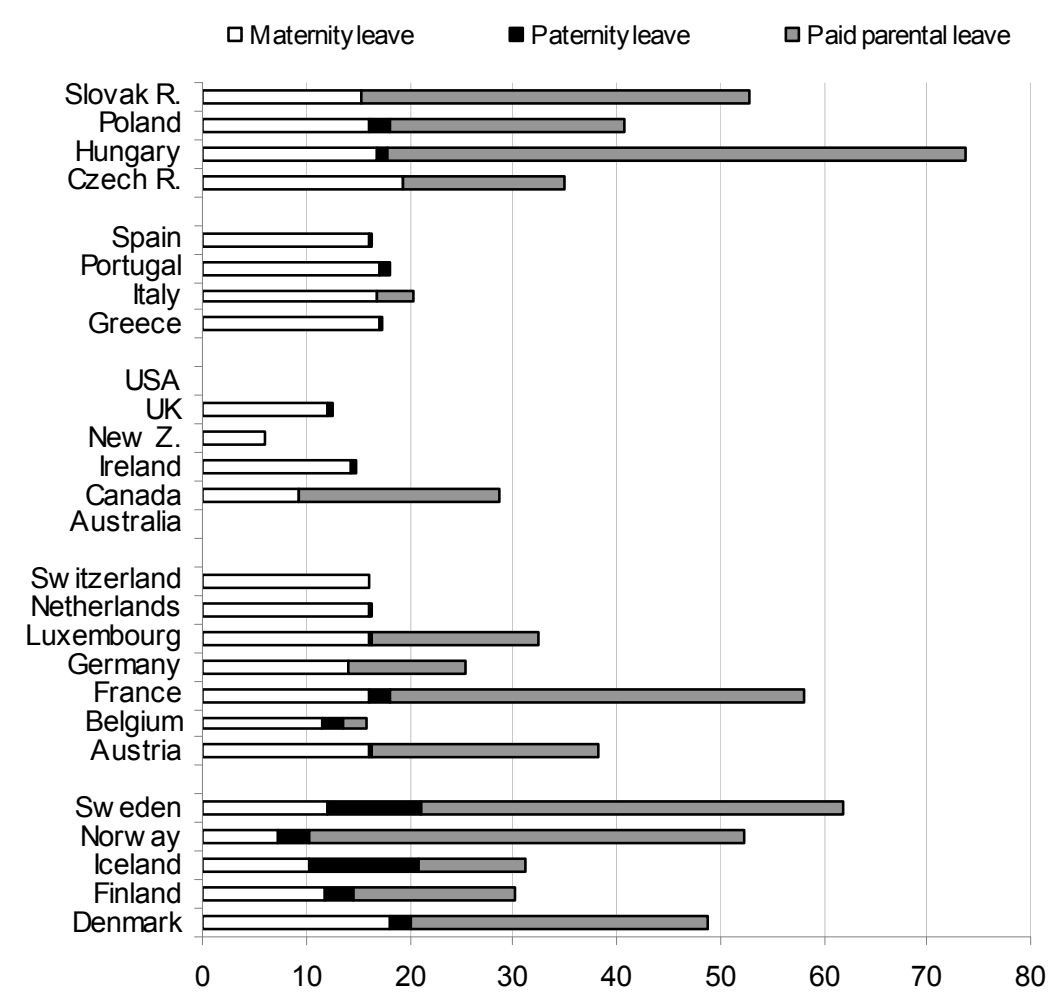

Note: All forms of leave are expressed as equivalent full-paid weeks (number of weeks of leave multiplied by percentage of wage or earnings received during the leave)

Source: OECD family policy database. Table PF7.1. Accessed at http://www.oecd.org/els/social/family/database

The Nordic countries also stand out in view of their high level of gender equality (as seen in Table 1 earlier). Among other things, this translates into a higher fathers' take-up rate of parental leave than in most other countries (Moss and O'Brien 2006). Fathers in the Nordic countries continue to take a smaller share of parental leave than mothers, but their participation has strongly increased in recent years especially following the introduction of specific measures (such as the fathers' quota in Norway in 1993). Another indicator of gender equality is fathers' participation in child care activities, Data in Figure 5 are based on timeuse surveys and express fathers' involvement in child care activities as a ratio of

$8 \quad$ It has to be noted that family policies are not the only factor affecting cross-national differences in the family pay (or motherhood penalty). Cross-national differences in the structure of earnings and of the labour market, and in women's employment trajectories, also matter. 
that of mothers. Again, the data sharply contrast the situation in the Nordic countries, with a relatively high participation of men in domestic activities, and that in southern European countries, with a much lower participation of men. And while participation of men in unpaid work is to some extent beyond political intervention, the strong regional and national differences obviously mean that men and women in different countries face very different realities when considering having a first or a subsequent child.

\section{Figure 4:}

\section{Child care provision, as of $2000-5^{a}$}
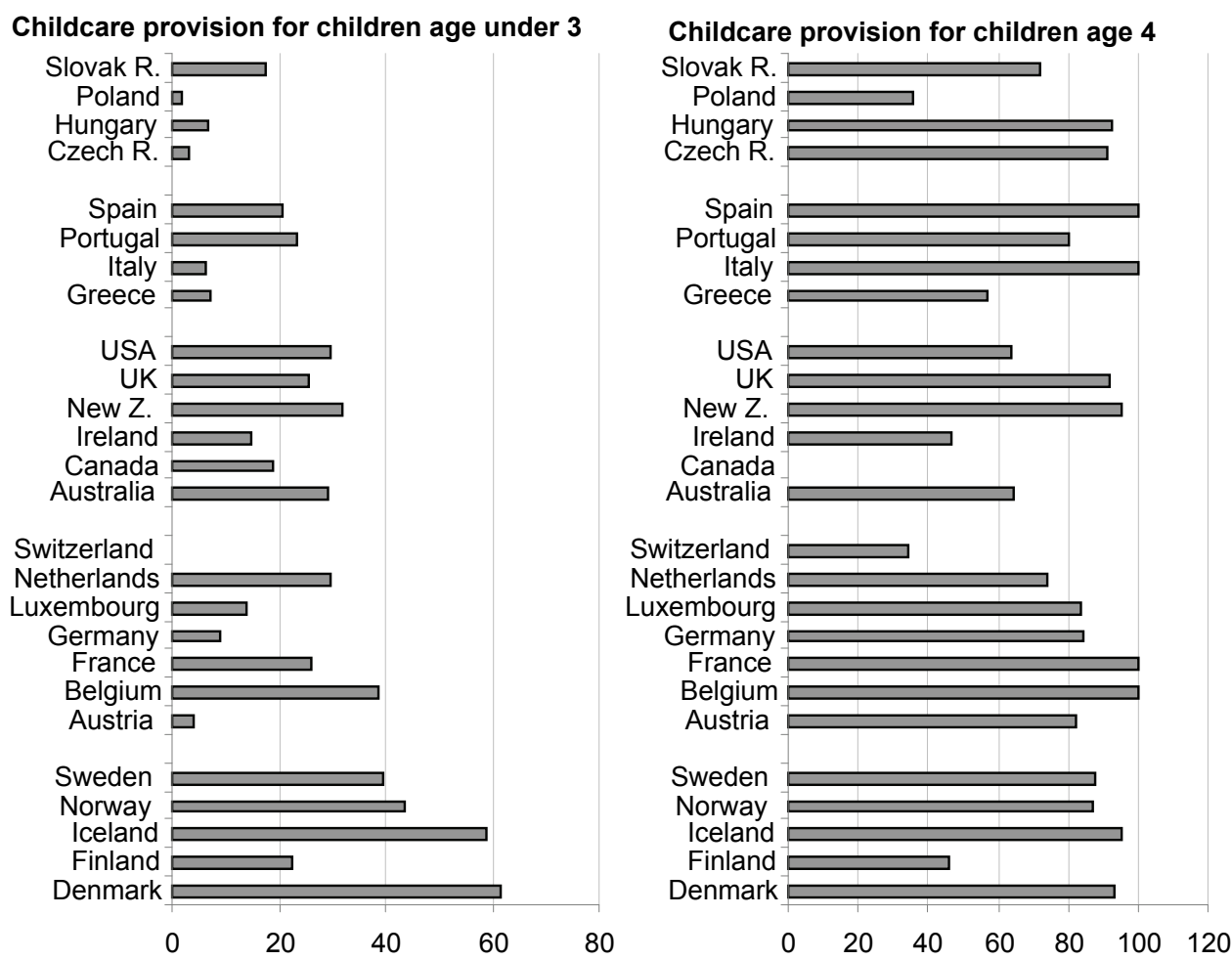

Note: a- Enrolment in daycare and pre-school. The actual year of the data varies across countries, but all fall in the period 2000-2005.

Source: OECD family database. Table PF11.1. Accessed at http://www.oecd.org/els/social/family/database

The key question, of course, is whether these strong regional and national differences in work- and gender-related contexts reflect similar differences in fertility. Once again, the empirical literature does not provide a conclusive answer to this question: it does nonetheless provide some plausible pieces of evidence. For example, the reviews by Andersson and by Rønsen and Skrede (pp. 89-102 and pp. 103-123) draw a possible link between higher-than-average fertility in the Nordic region and the family policies in these countries. However, they note that 
the latter policies have been implemented for the purpose of individual needs, and not to increase fertility: higher fertility thus being only a by-product of those measures. They also point out that work-family reconciliation policies in Sweden are individual-oriented, not family-oriented, and therefore do not encourage gender segregation in the family (Andersson, pp. 89-102).

\section{Figure 5:}

Ratio of fathers' to mothers' time spent on child care activities (per day), around 2000

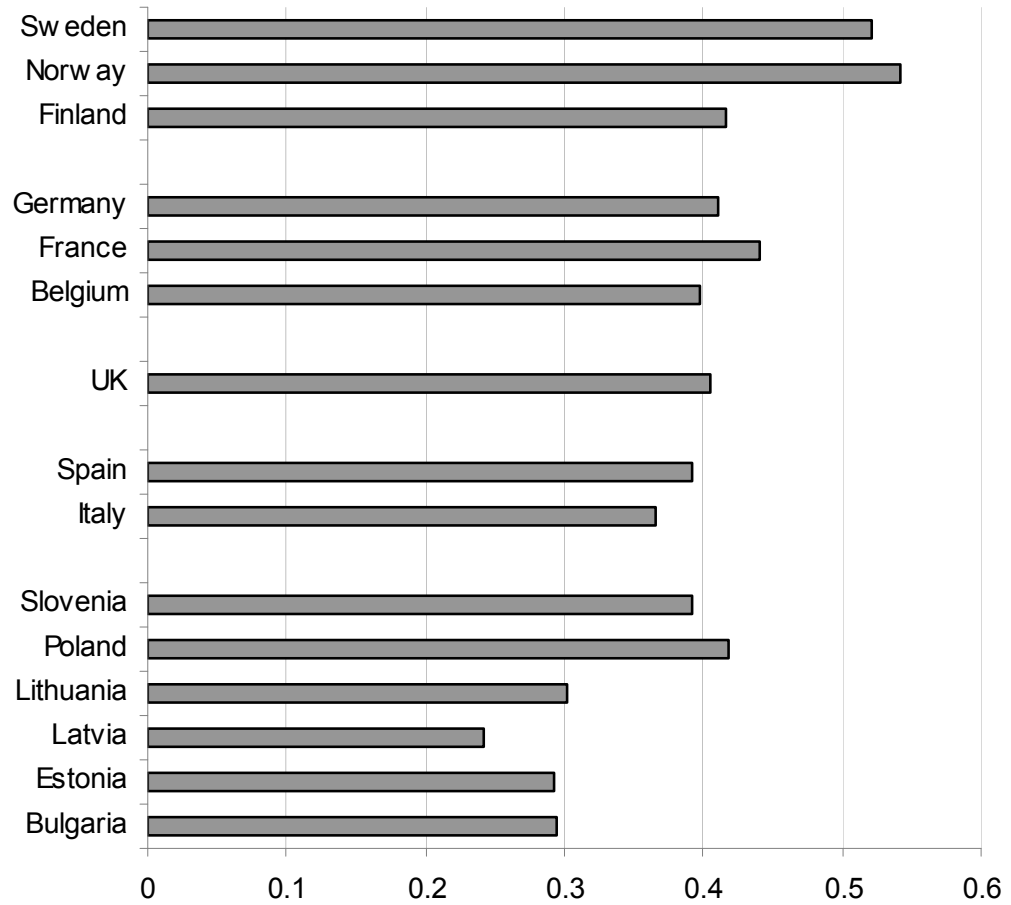

Note: the data refer to married or cohabiting parents whose youngest child is under the age of seven. Child care activities, as defined here, refer to time directly involved with the child, for example playing with, and reading to, the child as well as transportation related to the child.

Source: Data computed by the authors based on the HETUS dataset. Accessed at http://www.edacwowe.eu/en/frmShowGIW_indicators?v_id=14

The experience in the Nordic countries with respect to family policies shows that higher levels of gender equality correlate with higher levels of fertility. Is gender equality then a prerequisite for higher fertility? McDonald (2000) supports this view. However, as Rønsen and Skrede (pp. 103-123) note, gender relations are still unequal even in the Nordic countries. In particular, the higher-thanaverage fertility levels observed in these countries appear to co-exist with a 'gender equality light' division of work between parents (as opposed to a higher level of gender equality). Similarly, the higher-than-average level of fertility observed in France also co-exists without significant achievements with respect to 
gender equality. For instance, Pailhé et al. (pp. 149-164) indicate that the 1994 family policy reform in France extended parental leave up to the third birthday of the child but led to a pronounced decline in women's labour force participation. Thus, while fertility, gender relations and policies may be related, their actual combination may reflect broader societal norms and institutions, thus preventing broad generalisations across countries.

\section{Other institutional barriers to fertility and related policies}

While governments have focused their family policies mainly on financial and work-related measures, other macro-level factors may constitute barriers to fertility as well. The article by Rindfuss and Brauner-Otto (pp. 57-87) is particularly interesting as it discusses the possible role of three institutional factors that are usually not targeted by family policies: the educational system, the labour market and the housing market. These factors, they argue, can have a significant effect on fertility, especially through its postponement to older ages. In turn, the postponement of childbearing may result in lower levels of fertility because postponed intentions to have a child may remain unrealised later in life.

The possible link between policies and the timing of childbearing is a relatively new area of research and suggests that policies encouraging people to have their children at earlier ages may result in higher completed fertility. Lutz et al. (2005) call these policies tempo-related ones and argue that one way to achieve births earlier in life would be by shortening education (without compromising the actual levels of human capital) since most of the first births in contemporary Europe take place after the completion of education (Billari and Philipov 2004).

One other way that policies may stimulate earlier childbearing is through the encouragement of couples to have children within short birth intervals. A specific policy instrument of this kind known as the 'speed premium' was implemented in Sweden in the 1990s. As discussed by Andersson (pp. 89-102) and Rønsen and Skrede (pp. 103-123), 'speed premiums' had an undeniable effect on the tempo of childbearing and may have contributed to the higher fertility level observed in Sweden.

\section{Future avenues of research}

We noted in the introduction that the conference did not deal with the question of whether governments in Europe should intervene to increase fertility. Yet, the European Commission indicated its support to such an intervention in recent documents (including its Green paper on demography and its subsequent 
communication), ${ }^{9}$ and in February 2008 the European Parliament adopted a Resolution on the demographic future of Europe). One assumption behind this position is that fertility will remain low during the decades to come. Butz (pp. 3538) warns, however, that contemporary scientific research neither supports nor rejects such an assumption, and therefore policies may happen to be redundant. This is a valid point, especially considering the relatively poor accuracy of previous attempts at predicting future trends in fertility. Furthermore, policy interventions may have unanticipated negative effects (for example on gender equality) thus leading Botev (pp. 29-34) to call for a thorough assessment of the cost, benefits and impact of any policy.

Still, it remains that some countries, especially in southern and eastern Europe have experienced very low levels of fertility for nearly two decades. The impact of such fertility levels on the speed of population ageing and eventual population decline is undeniable, putting a huge pressure on policy makers to alleviate some of the negative consequences. To be sure, any policy intervention is bound to be very expensive and may be out of reach for countries with weaker economies.

Effective policy interventions also call for a sound understanding of the gap between actual fertility and desired fertility. While studies have identified some possible barriers to the realisation of fertility intentions, the instability of these intentions over the life course of individuals will require researchers to further investigate the broader context in which intentions are formed, altered, realised or not realised, both at the micro-level of individuals and at the macro-level of societies. In particular, and as suggested in this volume, economic obstacles to fertility and work-related ones may matter but so may other dimensions such as gender equality, the housing market and the educational system. For example, more possibilities for part-time work may be called for, as well as the introduction of tempo-policies (see Lutz in pp. 17-24). Further understanding of the barriers to fertility and the possible impact of policies will require access to comprehensive policy databases though. Thévenon (pp. 165-177) describes a number of such databases and illustrates how useful they can be. However, these databases will need to be extended to include information not only on the actual benefits provided by national governments but also on their eligibility criteria and take-up rates. They should also be complemented with information about regional as well as employer-provided policies.

And while policies may have some effect on fertility, they will probably not prevent population ageing and population decline, thus calling for major shifts in the ways societies define economic success, in the ways they view and encourage the contribution of older members of societies, and in the ways they adapt to their new demographic realities.

\footnotetext{
9 European Commission Green Paper "Faced with demographic change, a new solidarity between the generations" $\operatorname{COM}(2005)$ 94, European Commission Communication "The demographic future of Europe - from challenge to opportunity", $\operatorname{COM}(2006) 571$ final.
} 


\section{References}

Balter, M. 2006. "The Bomb That Wasn't.” Science 312: 1896.

Barach, C., R. King, and A. Yuan. 2005. "Children as private and public goods: implications of fertility trends." In: A. Booth and A.C. Crouter (eds.) The New Population Problem. Lawrence Erlbaum Ass.

Billari, F. C. and H.-P. Kohler. 2004. "Patterns of low and lowest-low fertility in Europe." Population Studies 58(2): 161-176.

Billari, F. C. and D. Philipov. 2004. "Education and the transition to motherhood: a comparative analysis of Western Europe." European Demographic Research Papers 3. Vienna, Vienna Institute of Demography, Austrian Academy of Sciences.

Bongaarts, J. and G. Feeney. 1998. "On the quantum and tempo of fertility." Population and Development Review 24(2): 271-91.

Bradshaw, J. and N. Finch. 2006. "Can Policy Influence Fertility?" In: H. Emanuel (ed.) Ageing and the Labour market: Issues and Solutions, International Studies in Social Security. Antwerp, Intersentia/FISS, pp. 151-168.

Caldwell, J. C., P. Caldwell, and P. McDonald. 2002. "Policy responses to low fertility and its consequences: a global survey." Journal of Population Research 19(1): 1-24.

CBS news. 2007. Russia's Answer For A Declining Population: Government Pays Families \$10,000 To Have A Second Child. May 12. Available online: «http://www.cbsnews.com/stories/2007/05/12/world/main2795139.shtml».

Gans, J. S. and A. Leigh. 2007. Born (Again) on the First of July: Another Experiment in Birth Timing. Available online: «http://works.bepress.com/cgi/viewcontent.cgi?article=1014\&context=joshuagans».

Gauthier, A. H. 2005. "Trends in policies for family-friendly societies.” In: M. Macura, A. L. MacDonald, and W. Haug (eds.) The New Demographic Regime Population Challenges and Policy Responses. New York, Geneva, United Nations, pp. 95-110.

Gauthier, A. H. 2007. "The impact of family policies on fertility in industrialized countries: a review of the literature." Population Research and Policy Review: 323-346

Goldstein, J., W. Lutz, and M. R. Testa. 2003. "The emergence of Sub-Replacement Family Size Ideals in Europe." Population Research and Policy Review 22(5-6): 479-496.

Inglehart, R. and W. E. Baker. 2000. "Modernization, cultural change, and the persistence of traditional values." American Sociological Review 65: 19-51.

Kim, Y.-I. A. 2007. Impact of Birth Subsidies on Fertility: Empirical Study of Allowance for Newborn Children, a Pronata Policy. Available online: «http://home.uchicago.edu/ kimyia/Kim\%20(2007).pdf».

The Korea Herald. 2003. Seoul to use tax breaks to increase birth rate. 26 August 2003.

Lunn, S. and L. Wilson. 2008. "Time to rethink baby bonus." The Australian. March 14. Available Online: «http://www.theaustralian.news.com.au/story/0,25197,233719632702,00.html».

Lutz, W. and V. Skirbekk. 2005. "Policies Addressing the Tempo Effect in Low Fertility Countries." Population and Development Review 31(4): 699-720.

McDonald, P. 2000. "Gender equity, social institutions and the future of fertility." Journal of Population Research 17(1): 1-16. 
Milligan, K. 2002. Quebec's Baby Bonus: Can Public Policy Raise Fertility? Backgrounder, C.D. Howe Institute, January, 2002.

Moss, P. and M. O'Brien (eds.) 2006. International Review of Leave Policies and Related Research 2006. UK Department of Trade and Industry. Available online: «http://www.berr.gov.uk/files/file31948.pdf».

Quesnel-Vallée, A. and S. P. Morgan. 2003. "Missing the Target? Correspondence of Fertility Intentions and Behavior in the U.S." Population Research and Policy Review 22(5-6): 497-525.

Rostgaard, T. 2004. Family Support Policy in Central and Eastern Europe - A Decade and a Half of Transition. UNESCO Education Sector. Early Childhood and Family Policy Series $N^{\circ} 8-2004$. Available online:

«http://unesdoc.unesco.org/images/0013/001337/133733e.pdf».

Saxonberg, S. and D. Szelewa. 2007. "The continuing legacy of the Communist legacy? The development of family policies in Poland and the Czech Republic." Social Politics: International Studies in Gender, State and Society 14(3): 351-79.

Sigle-Rushton, W. and J. Waldfogel. 2007a. "Motherhood and women's earnings in Anglo-American, Continental European, and Nordic countries." Feminist Economics 13(2): 55-91.

Sigle-Rushton, W. and J. Waldfogel. 2007b. "The incomes of families with children: a cross-national comparison." Journal of European Social Policy 17(4): 299-318.

Špidla, V. 2007. Commission declaration on childcare. Plenary session of European Parliament, Strasbourg, 13th March 2007. Available online: «http://ec.europa.eu/employment_social/speeches/2007/vs_070313_en.pdf».

Stewart, K. and C. Huerta. 2006. "Reinvesting in children? Policies for the very young in South Eastern Europe and the CIS." Innocenti working paper 2006-01. (Unicef, Innocenti research center).

Testa, M. R. 2006. Childbearing preferences and family issues in Europe. European Commission. Available online: «http://ec.europa.eu/public_opinion/archives/ebs/ebs_253_en.pdf».

Testa, M. R. 2007. "Childbearing preferences and family issues in Europe: evidence from the Eurobarometer 2006 survey." Vienna Yearbook of Population Research 2007: 357-79. 